\section{Psychological ownership development in new venture teams}

\author{
Olga Yttermyr \\ Linköping University, Sweden
}

\section{Karl Wennberg}

Stockholm School of Economics, Sweden
International Small Business Journal: Researching Entrepreneurship

(c) The Author(s) 2021

\section{(c) (i)}

Article reuse guidelines: sagepub.com/journals-permissions DOI: 10.1 I 77//026624262। I 023380 journals.sagepub.com/home/isb

@SAGE

\begin{abstract}
Psychological ownership (PO) is important for organisational climate and outcomes, yet, little is known about collective forms of PO in emerging entrepreneurial teams. Based on an in-depth study of a new venture team over three years, we sketch a process model of collective PO development. While studies on individual PO in established organisations highlight individual needs in triggering processes of PO development, our study indicates the importance of temporal, role-based, and input-based alignment of interpersonal processes for the emergence of collective $P O$ in new venture teams. We discuss insights for research on new venture teams and research on small groups.
\end{abstract}

\title{
Keywords
}

emerging states, new venture teams, process study, psychological ownership

\section{Introduction}

The rapidly expanding research on new venture teams (NVTs) has unearthed important knowledge regarding team inputs such as demographic composition, member experiences and motivations, and effects on various outcomes in NVTs. However, we still have limited knowledge about the interpersonal processes that NVTs undergo as they develop (Bjornali et al., 2017; Davidsson and Gordon, 2012; Klotz et al., 2014). Furthermore, while research on small groups highlights interpersonal processes - team member experiences and interactions directed towards task accomplishment - as vital foundations of the 'emergent states' shaping the relationship between team inputs and outcomes (Mathieu et al., 2008: 422), little is known about the dynamic team-based emergent states that arise from such processes in NVT contexts (Ben-Hafaïedh, 2017; Klotz et al., 2014). To begin addressing this gap, we study the interpersonal processes underlying the development of the emergent state of psychological ownership (PO) in new ventures.

\section{Corresponding author:}

Karl Wennberg, House of Innovation, Stockholm School of Economics, PO Box 650I, Stockholm I I383, Sweden.

Email: karl.wennberg@hhs.se 
Enhancing our understanding of PO in NVTs is important for several theoretical and empirical reasons. First, feelings of ownership have a strong influence on goal achievement and early success in new creative teams (Alper et al., 1998), especially when social norms are weak (Pierce et al., 2003). However, the psychology of 'mine' may also be manifested in protective behaviours and territoriality (Avey et al., 2009). Thus, we need to understand how, when, and why collective PO emerges. To date, collective psychological processes have received limited attention in research into NVTs (Gray et al., 2019; Hjorth et al., 2015). For example, studies of PO in small groups such as family firms (Pittino et al., 2018) or small- and medium-sized enterprises (SMEs; Ikävalko et al., 2010) have been limited to treating PO as an independent variable or a mediator explaining successes and failures.

Second, the theory of PO suggests that feelings of possession over an organisation are likely to increase as people go through the processes (or travel the paths) of investing time and energy into it, learning more about it and gaining feelings of control over it (Pierce et al., 2001). However, we cannot readily assume such a linear path of collective PO development in new ventures, which operate under conditions of uncertainty where entrepreneurs must not only identify what they need to do to reach their goals, but also constantly re-examine and reassess those goals - even as they establish new identities as entrepreneurs (Grimes, 2018).

We seek to address these parallel voids in the PO and team entrepreneurship literatures by developing a process model of collective PO development in new ventures, based on a qualitative longitudinal study of an NVT during three years of its initial development, interviewing all team members and key stakeholders. Through careful primary and secondary coding of team member expressions of feelings, attitudes, and expectations towards each other and the venture, we derive a multi-level process model of PO development in NVTs that highlights the reciprocal nature of PO and the varying self-identity, stimulation, belonging, and self-efficacy of team members. Our study emphasises the context-dependent nature of PO development in entrepreneurial settings where roles overlap, members work under resource constraints, and social norms are still emerging. Our empirical findings and suggested model emphasise that ownership feelings in a diverse team can appear at different stages of venture development and be of different strengths - which, in turn, may cause dissatisfaction and poor coordination, despite strong individual commitment.

This article provides two key contributions. First, our longitudinal study and process model contribute to entrepreneurship research by highlighting the affective emergent state of PO as essential to the overall climate within NVTs, and its development over time. The empirical study identifies a set of psychological needs that induce entrepreneurs to travel a fourth, unexplored path towards PO - that of entrepreneurial creation and co-creation. We explain the importance of this path for understanding PO in NVTs and discuss the broader relevance of our process model for entrepreneurial team research, which is gradually moving from analysing input-output relationships towards paying greater attention to the temporal issues affecting team development (Collewaert et al., 2016; Sklaveniti, 2017). Specifically, our study heeds recent calls for research on the creation of emergent states in nascent teams (Klotz et al., 2014; Waller et al., 2016) involving multi-level processes 'beginning with individuals but ending with a transformed structure' (McMullen and Dimov, 2013: 1507). Second, our study extends extant PO models by scrutinising the interplay between the four paths and its role in PO development (Pierce et al., 2001). While extant models highlight the benefits of strong PO for motivation and task fulfilment, our findings point to a risk that while strong individual PO is necessary for the development of feelings of creative community and enhanced entrepreneurial identity, strong individual PO is not in itself a sufficient condition for the development of strong collective PO. This reveals the contextual limitations of PO models that reflect established organisations; they are less relevant to highly self-organising and more uncertain contexts such as new ventures, where role-based, temporal, and input-based asymmetries are likely to affect the 
process of collective PO development. Our article discusses the theoretical reasons behind such asymmetries, their implications for entrepreneurial team development and the broader implications for research on NVTs and psychological research on small groups.

The article is structured as follows. We commence by introducing our theoretical pillars, building upon extant research on PO emergence in the context of entrepreneurship. We highlight key theoretical insights and unexplored areas, focusing specifically on the challenges of process-based research on PO as an emergent state. We then explain our research methodology and present our findings from the case study. Since the findings emanate from a longitudinal process study, we organise them into themes based on the four paths that the venture team travels towards the development of a shared feeling of PO. We capture both earlier and later stages in the process, discussing the interplay between the four paths. In the 'Discussion and conclusions' section, we analyse the role of identified team asymmetries in the collective path travelled, and the pattern of collective PO emergence. We conclude by outlining the study's theoretical and empirical contributions and its limitations, and present suggestions for future research and implications for practitioners and stakeholders who seek to support team entrepreneurship.

\section{Theoretical pillars}

\section{The 'what' of emergence: PO as an emergent state}

The concept of PO focuses on the psychological needs that PO fulfils among individuals, as well as on the mechanisms of PO emergence (Pierce et al., 2001, 2003). PO has been defined as 'that state in which individuals feel as though the target of ownership (material or immaterial) or a piece of it is "theirs" (Pierce et al., 2001: 299), as an extended self.

The affective core of PO suggests that emotional experiences and feelings of possession create an emotion-laden psychological attachment to the organisation that transcends mere cognitive understanding (Van Dyne and Pierce, 2004: 442). In turn, PO triggers affect-driven behaviours, creating emotional bonds between individuals and influencing organisational climate, which is essential for collective PO development (Pierce and Jussila, 2010). Emergent team states such as respect, trust, and cohesion have been shown to positively affect group satisfaction and cooperation, thus improving group performance (Mathieu et al., 2008). Similarly, the emergent state of PO has been suggested to promote feelings of organisational commitment, citizenship behaviours, work persistence and emotional wellbeing. Research has shown that PO can have a reciprocal relationship with organisational behaviours, based on positive attitudes towards the organisation (commitment and work satisfaction), proactive behaviour and discretionary extra-role activities that contribute to both organisational and individual performance (Avey et al., 2009; Mayhew et al., 2007; Van Dyne and Pierce, 2004). Caring, making personal sacrifices, taking risks and nurturing the organisation can coexist with preventive behaviours such as territoriality and with emotions such as frustration and stress (Avey et al., 2009). Such behaviours can both originate from ownership feelings and also cause them as part of an ongoing process (Pierce and Jussila, 2010). PO is here seen as distinct but related to theories such as entrepreneurial identity formation (Grimes, 2018) and identification with a venture (Powell and Baker, 2017). Identity, identification and PO are all examples of process theories of entrepreneurial emergence (Hjorth et al., 2015).

Attempts to explain the presence and importance of emergent states still neglect the dynamic nature of these constructs in terms of group member interaction processes and the behavioural patterns underlying their emergence over time (Waller et al., 2016). Both small-group research and organisational studies highlight the need for such a focus in order to understand temporal patterns of emergence (Marks et al., 2001), the 'strength' of emergence (Waller et al., 2016) and the 
interplay of individual and collective manifestations of emergent states (Mathieu et al., 2008). Similarly, Dawkins et al. (2017) note that current PO research lacks a process perspective, arguing for longitudinal studies.

\section{The 'where' of emergence: the new venture as a target of PO}

PO research highlights that the nature and characteristics of the organisation defining the 'target of ownership', will direct and facilitate member actions or 'pathways' towards feeling of ownership. Still, this research has yet to reveal much about the contextual nature of PO development (Ikävalko et al., 2010). New ventures constitute different kinds of PO target from established organisations. The new venture idea must be attractive and accessible in order for the individual to make the emotional investment that will make the new venture 'theirs' (Pierce and Jussila, 2011). At the same time, a new venture is inherently novel and ambiguous, making it a target with an unclear identity, and the subject of a process of discovery and creation where entrepreneurs need to manage uncertainty, while striving for efficacy and a sense of control (Grimes, 2018; Packard et al., 2017). As such, ownership here extends beyond legal and financial ownership towards personal identification with, and commitment to, the venture. During the process of PO development, the venture becomes part of the entrepreneur's self - an extension of the individual and their identity - which triggers their identity work (Leitch and Harrison, 2016; Pierce et al., 2003). Research into entrepreneurship has increasingly focused on venture founders and their remarkably strong psychological attachment to the venture and the idea behind it (Wasserman, 2017). Psychological ties and ownership have been studied as variables moderating processes of founder identity work (Grimes, 2018), persistence (Gimeno et al., 1997), perceptions of control (Wasserman, 2017) and disengagement (Collewaert et al., 2016; Rouse, 2016). PO and legal ownership are not mutually exclusive, suggesting that legal owners often exhibit high PO, since legal ownership creates legitimacy and enhances feelings of stability and control. Yet, research on NVTs shows that much of their teamwork is based on trust and commitment rather than formal documentation of ownership (Breugst et al., 2015). ${ }^{1}$

\section{The 'why' of emergence: satisfying ownership needs}

Research into the emergence of PO theorises that four innate individual psychological needs are necessary - but not sufficient - conditions for PO to develop. They are the need for belonging (a sense of place, home and security in place and time), the need for efficacy (the ability to control one's environment and oneself, show competence and exercise influence), the need for self-identity (getting to know and define oneself better through possessions) and the need for stimulation (deriving satisfaction from activation and arousal; Pierce and Jussila, 2010). By satisfying these needs in the venture, individuals get a feeling of ownership and see the venture as part of their extended selves. The process of PO emergence is thus a process aimed at satisfying the four needs. The emergent state of PO manifests increased feelings of satisfaction, comfort and security, creating a basis for positive experiences and behaviours. In an NVT context, these may be stabilising factors in the unpredictable and often disruptive entrepreneurial process, promoting trust and persistence (Mathieu et al., 2008; Zhu et al., 2013).

The concept of collective PO, in turn, builds upon social needs such as trustful relationships, social bonding and group belonging, which are satisfied through interaction and interpersonal processes (Pierce and Jussila, 2010). Our study focuses on the emergence of collective PO, which theoretically constitutes more than the sum of its individual parts (i.e. the satisfaction of individual needs). Yet, there is a dearth of knowledge in the literature on how such collective PO emerges. Understanding patterns of collective PO emergence is particularly important for NVTs, where 
outcomes are often a result of the entrepreneurial efforts of a team, rather than separate individuals (Cooney, 2005). When NVT members jointly invest time, energy and often personal identity into a venture, this process may trigger an overlap between their perceived selves, the team and the venture (Pierce and Jussila, 2011; Rouse, 2016). Pierce and Jussila (2010) suggest that collective PO reflects the need for collective social identity, where collective PO emerges if individuals experience themselves as psychological owners, feeling the comfort of being part of a team with similar ownership claims.

\section{The 'how' of emergence: the process of travelling the paths to PO}

PO is posited to emerge if the individual acts (travels the paths) in order to fulfil their ownership needs. These paths include obtaining and exercising control of the organisation (efficacy), coming to intimately know the organisation and investing time and energy (sacrificing part of the self) into it (Pierce et al., 2001). Since there appears to be a little evidence indicating which path may be the most effective for the emergence of PO (Pierce et al., 2003), a combination of paths and underlying factors may influence its development. Each team member can develop feelings or ownership as a result of having travelled these paths. Furthermore, the team also needs to build relationships and develop a collective social identity. As individuals travel the paths together, they are involved in interpersonal processes where they share experiences of collective action and social bonding (Mathieu et al., 2008). Collective travels result in the emergence of collective PO, where team members come to feel that the venture is jointly 'theirs'. This feeling is based on joint recognition of shared control, shared intimate knowledge of the venture and shared self-investment by team members (Pierce and Jussila, 2010).

However, when this process of travelling the paths takes place in a creative and innovative new venture environment, it may diverge for individuals with different roles (founders, employees, other stakeholders) and different views of the venture. NVT members may also join the venture at different times and disengage from or exit the venture, which may affect the development of PO on both individual and collective levels (Gray et al., 2019; Pierce and Jussila, 2010). Furthermore, many NVTs have a social identity that is initially weak, reflecting individual differences where members may have divergent reasons for working in the venture, potentially conditioning their propensity for innovative behaviour, the urge for creativity and the degree of entrepreneurial passion (Collewaert et al., 2016; Rouse, 2016).

\section{The unexplored emergent state of PO in NVTs}

Team entrepreneurship is an inherently collective endeavour, but current models of PO by and large ignore the potential for different manifestations of individual and collective PO. PO research builds on explicit or implicit assumptions that individual and team paths to PO are symmetrical in terms of temporal, emotional and role-based processes (Pierce and Jussila, 2010, 2011). Such assumptions may not hold for NVTs where creative individuals join the venture at different stages with different individual experiences and motives (Gray et al., 2019). Founders may become psychologically disengaged while employees may take over the venture idea and develop it further (Rouse, 2016). Such processes highlight the relevance of studying also how collective travels down the paths to PO, and the extent to which these paths are symmetrical with individual processes in the team. Research on emergent states theorises that groups and teams can be seen as cases of 'strong' emergence because of the interplay of macro and micro levels (Waller et al., 2016). While weak individual PO may give rise to weak collective PO, a strong identification by founders with the venture may produce strong and convincing feelings of PO in the team. Similarly, a combination of strong and weak individual 
PO may lead to strong but unstable feelings across the team. Gray et al. (2019) study 79 universitybased NVTs, finding that collective PO and performance in NVTs are influenced by territorial and help-seeking behaviours. Yet, their process model does not attend to team dynamics in terms of changes in needs or paths to PO, nor how they are manifested over time. Since PO is related to creativity and innovation in dynamic ways (Grimes, 2018), a process perspective is needed in order to highlight the dynamics of stronger or weaker PO emergence on different levels over time (Dawkins et al., 2017; Sklaveniti, 2017; Waller et al., 2016).

In this article, we argue that entrepreneurs have distinct psychological needs that we must recognise if we are to understand the process of collective PO emergence. Research on PO has yet to consider the psychological needs of individuals who exhibit creative behaviours in the context of entrepreneurship. NVTs face challenges and setbacks of different kinds, which may facilitate intimate knowledge and enhance the sense of control, while helping entrepreneurs to establish their own identity and role in the venture. Challenges may also induce the entrepreneur to invest even more of themselves into the venture, since persistence in the face of adversity is related to higher efficacy expectations (Bandura, 1997: 193). In their study of family firms, Zhu et al. (2013) found that strong PO may promote desire of the entrepreneurs to persist with the venture and develop it further, rather than quitting or stepping back from decision-making. Furthermore, Grimes (2018) argues that strong PO may lead to resistance to feedback, making the entrepreneur pursue the idea even further, despite signs of difficulties. Thus, entrepreneurs may travel paths towards PO that reflect their urge for creativity and novelty. Our article thus seeks to consider entrepreneurial needs and behaviours in the emergence of collective PO in a new venture as a distinct target of ownership.

A challenge in studying collective PO is that feelings of ownership and related attributes are self-reported by individual members. The conceptual core of PO suggests that individual routes down the paths reflect only personal experiences. Yet, emergent states are a function of team inputs, processes and outcomes emanating from lower level properties such as individual behaviours and patterns of interaction (Marks et al., 2001). We seek to overcome the aggregation challenge by following Waller et al. (2016), who conceptualise emergent states as global (emerging from individual levels), coherent (having an enduring identity as wholes for a period of time), ostensive (experienced and recognised by team members) and novel (previously non-existent), in line with the literatures on PO (Dawkins et al., 2017), entrepreneurial processes of co-creation (Sklaveniti, 2017) and identity formation (Leitch and Harrison, 2016).

\section{Case study data and methods}

This study originates from a larger project on the interpersonal dynamics in NVTs, with our case study emerging from a pre-study based on semi-structured interviews with founders, employees and other team members in 18 technology-intensive ventures in Sweden. The ventures were selected based on shared features such as age (younger than a year), product (hightech products), team background (mostly inexperienced), environment (incubator) and stage of development (prototyping and customer verification). Since our interest was in interpersonal processes, we aimed to discern the propensity of venture teams to engage in entrepreneurial activities where changing patterns of interpersonal behaviours could be manifested. In the initial exploratory phase studying a larger sample of ventures, we developed a semi-structured interview protocol based on our collective understanding of key processual elements in the entrepreneurship and team-process literatures (Klotz et al., 2014; Mathieu et al., 2008), where we systematically compared and contrasted the teams to identify interesting emergent findings (Yin, 1989). Interviews were supplemented with secondary data from websites and interviews with coaches, focusing on potential relationships with investors; technology and intellectual 
property; current stage of venture development, including customer contacts; emerging business model and financial conditions. Since many interviewees related their actions to feelings of ownership in the venture, the exploratory pre-study provided valuable insights into interpersonal processes in NVTs and strengthened our interest in PO as an emergent state that could explain diverse behavioural patterns in member interaction. Realising the limited scope of knowledge of PO in NVTs, we followed Siggelkow's (2007) advice to select a representative case providing a persuasive and detailed illustration of team dynamics and PO pathways, thus helping 'sharpen existing theory by pointing to gaps and beginning to fill them' (p. 21). Here, our case study provides a representative process of new venture development based on a theoretically informed criterion set in the exploratory data collection phase: medium diversity in formal ownership, medium level of technological opportunity, discernibly vivid team dynamics among the six members and clear indications of varying levels of emergent PO in the team (Breugst et al., 2015). The venture was a start-up developing a high-tech device in the sports industry, involving both hardware and software design.

A vital factor in our choice of case was the fact that the team consisted of two initial experienced founder-managers who recruited an operational team of members (henceforth called the 'op team') who joined the venture in an incremental way (initially unpaid, later paid with ownership shares). The op team became increasingly active in day-to-day activities, while the founders became increasingly passive, letting the op team develop the venture and subsequently appointing one of them as CEO. The enthusiastic op team worked hard on venture development, while the founders maintained the importance of their initial idea. We followed the NVT for three years from its foundation, until it dissolved because it failed to reach major milestones such as establishing a stable customer base, realising a well-functioning business model and attracting sizable investment.

We wanted to capture possible temporal and other asymmetries in the development of PO on the individual and collective levels. To do so, we engaged in a longitudinal study, interviewing all owners, founders, employees, the team coach and other team members such as temporary interns. This comprised 25 semi-structured interviews lasting between one and two hours each, ${ }^{2}$ covering topics such as individual and joint experiences of investing financial, human and emotional resources in the venture; interaction and negotiations with co-workers and stakeholders and episodes of experienced control (or lack thereof) over the venture's development, as it faced adversity and enjoyed success.

As we arranged access to the venture and discussed the study design, we realised that the concept of possession needed a set of elaborate and open-ended questions, since initial interviews suggested that the attributes of ownership were differently interpreted by respondents. We tried to avoid focusing on legal ownership, which would omit the elements central to understanding PO. Following Ikävalko et al. (2010), we sought to overcome this challenge by avoiding the words 'owner', 'ownership' and derivatives. Instead, we put a strong emphasis on 'mine', 'ours', 'part of me' and similar expressions. We focused on capturing the needs and paths leading to PO. These were easier for respondents to recall when we asked them to reflect on actions, decisions and attitudes during particular episodes of venture development, where meeting the needs ('why') and travelling the paths ('how') indicates emerging PO. Since time is a key ingredient for emergent states (Waller et al., 2016), we focused on similar topics in interviews with all team members and stakeholders at every interview round.

During the process of data collection, and especially at the initial stages, we collected and analysed data in an inductive manner. The first round of interviews covered topics such as the venture idea, goals, plans and strategies. We also mapped team member backgrounds, roles, entrepreneurial experience and perceptions of the venture. Our aim was to identify the initial steps that the 
members made along the paths towards ownership feelings for the venture, and the reasons behind them. Keeping in mind the affective core of the PO concept (Van Dyne and Pierce, 2004), we carefully captured expressions of emotions such as joy, fury, excitement and desperation. Thus, we could see how, and why, respondents chose to travel the paths towards PO, both individually and together. The data were coded according to the principles proposed by Gioia et al. (2013). Subsequent semi-structured interviews came to focus on the subjects and additional themes emerging from the data.

\section{Analytical methods}

In our initial interviews, we focused on frequently recurring phrases reflecting motivational explanations of participation in the NVT development process. We captured respondent statements identified as needs, or motivational triggers, which were then systematically coded and combined into clusters of needs. Thus, we could surface first-order codes such as, for instance, 'feeling inspired by risk and opportunity' and 'making active personal contributions to the product'. In subsequent interviews, we used the results for op team members to reassess the needs and need clusters on both individual and collective levels, to capture expressions that would indicate that the members were taking action to satisfy some of these needs. This progressive focusing allowed us to capture tentative relations between concepts and provide detailed understanding of the concepts, thus working in an iterative manner with our process data and theory (Orton, 1997), given the specifics of the NVT context (Neergaard and Ulhøi, 2007). Follow-up questions also came to focus on actions of individual members and their consequences on a collective level, and vice versa, maintaining an awareness of aggregation problems from individual to team-process descriptions (Mathieu et al., 2008: 419).

Focusing on specific actions that satisfied certain needs, or initiated other actions and potentially triggered other needs, we tried to distinguish between the 'why' and 'how' of emergence, thus, identifying paths to feelings of ownership. We did this by asking the team members to explain their actions and reflect on what caused them, and why. In order to capture team development over time, we asked team members to reflect on each other's actions, feelings and expectations in every interview, paying careful attention to manifestations of collective action at different stages. To contextualise our data, we also paid attention to the venture idea and its modifications, which are central to the entrepreneurial process in NVTs (Grimes, 2018). For instance, we noted a shift when the team decided to include much more software in the product than initially intended, which modified how they distributed tasks, and a shift in marketing strategy when the team aborted a plan that had been carefully prepared for months, alerting all members to the critical lack of sales.

Once the work with initial op team members showed signs of data saturation, we engaged in axial coding. First, we identified nine aggregated categories of needs, where we chose to attach a tag such as 'the need to do something', related to a desire for specific actions and thus explaining these actions. To create a processual model of PO development, we also documented whether these needs grew stronger or weaker during the venture development process, as well as eventually triggering feedback loops and enhancing or weakening each other. By linking the needs to specific actions and searching for the paths as aggregate categories of these actions, we identified secondorder themes such as 'individual identity work' and 'getting better knowledge of the team'. The second-order themes supported our finding that the interviewees accounted for their needs as motives for specific actions. Thus, these overarching themes reflected the entrepreneurial actions of the team, and also allowed us to step back from individual needs and focus on interpersonal processes. This, in turn, revealed the elements of what we identified as four paths to PO, also capturing the complexity of PO development over time on an aggregated level. 
The richness of the data allowed us to capture the relationships between the four paths over time, which we highlight in our data structure overview (Table 1) and visualise in our process model (Figure 1). We found that some of the paths and their constituent elements were central to the development of PO, while others were secondary, or supplementary. Furthermore, the longitudinal data showed that the paths were non-linear, with actions affecting needs and consequently creating new paths or loops. This suggests that collective PO could be the result of a complex, asymmetric and even disruptive temporal interplay between individual PO of heterogeneous members. Importantly, we found that the three paths to PO suggested in the literature are heavily influenced by an additional fourth path, which we identified as participation in entrepreneurial creation. This path has not been suggested in previous PO literature.

Based on our analysis of the interplay of the four paths over time (based, in turn, on changes in psychological needs over time), our data also highlighted a number of asymmetries that seemingly influenced the process of collective PO development. These asymmetries reflected our persistent focus on both membership composition and team development over time. This helped us explain our observation that collective PO does not necessarily correspond to individual PO, which could partly account for why the studied venture failed. This finding suggests that understanding asymmetries in the development of PO over time can enhance our knowledge of new venture performance.

\section{Findings}

From the start of our interviews, the study participants indicated a strong sense of being part of an entrepreneurial journey, rather than a particular project. They linked the venture, the idea and the team to their own values, expectations and entrepreneurial aspirations. Each respondent clearly indicated that the urge to be part of a creative process was central for their personality, and described the team as very creative, with an entrepreneurial mind-set. The two experienced founders and the four inexperienced op team members all expressed similar passion at the beginning of our study. Even at later stages, when the venture was struggling and tension within the team was increasing, we continued to hear similar expressions - especially from the op team, who also proudly referred to their increased entrepreneurial experience, knowledge and self-esteem. Despite frustration with poor venture performance, they expressed the sense of fulfilment as entrepreneurs. We could see that passion as a deep driving force for their actions throughout the journey, as they invested their time, money, energy and personality into the venture, even in times of distress. Responses to the recurring interview question why the team members were part of this process revealed their desires and needs. We noted that these needs gave rise to actions, and to the emergence of new feelings.

Table 1 summarises the PO processes gleaned from our coded data. The 'paths towards PO' outlined in column 4 reflect the theoretically informed processes of PO development recognised in previous PO literature: investing the self, developing deeper knowledge and establishing and exercising control. However, our findings show strong evidence of a fourth process, which we call participating in creation. Based on our first-order coding of the data (column 1), we identify the different needs that these four processes satisfy. We find that the entrepreneurial process of creation and participation in joint creation serves to satisfy the entrepreneurial needs of creation. We find these needs prominent in our data, and we, therefore, choose to place the entrepreneurial process first in our table, thus highlighting its fundamental importance to the development of PO in the team. We further derive nine second-order themes (column 3) by which these PO processes are identified in the NVT process we follow. Column 2 of Table 1 highlights variations in these themes across individuals and time stamps in the data. Our second-order themes represent how clusters of needs in column 1 are manifested in actions or the desire for action, thus showing how 'travelling the paths' towards PO unfolded. Representative quotes (see Appendix 2) are used to illustrate this 

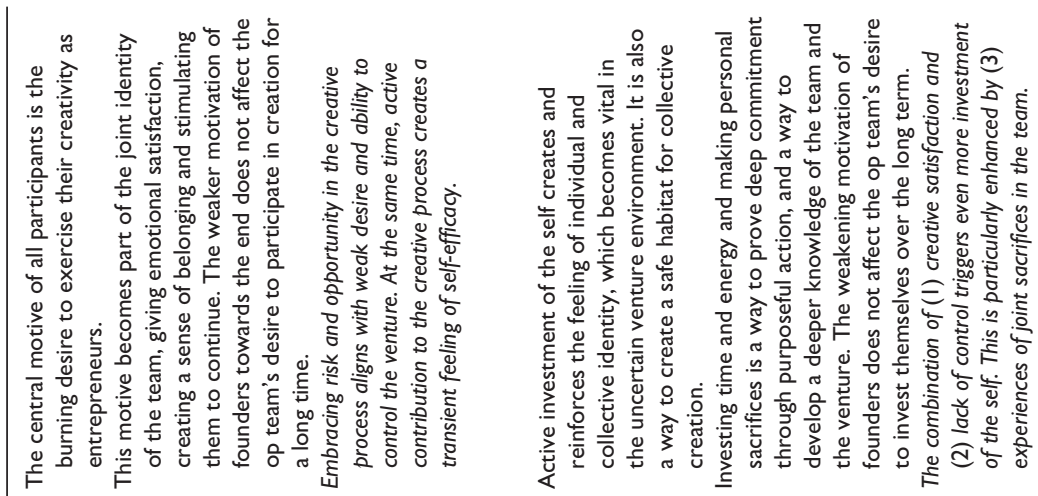

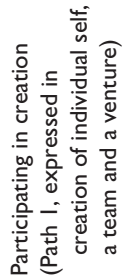

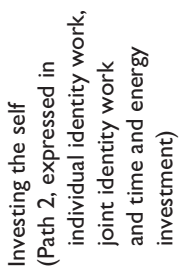

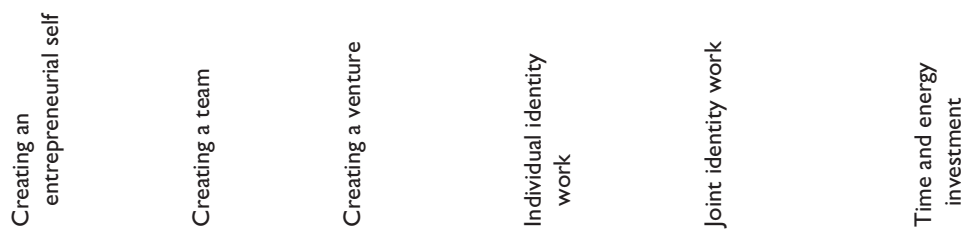

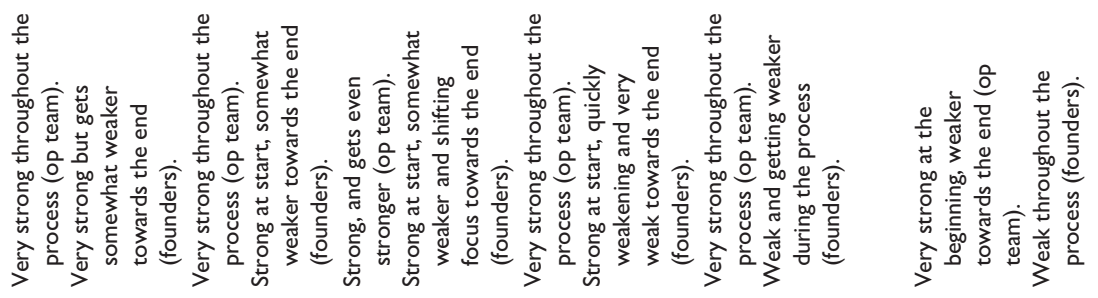

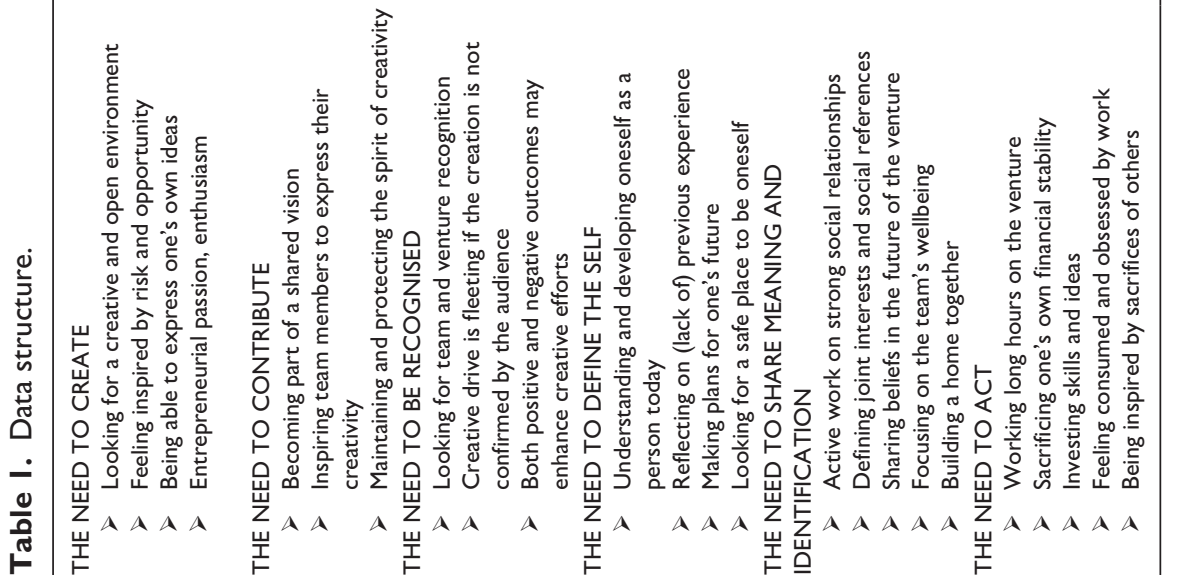




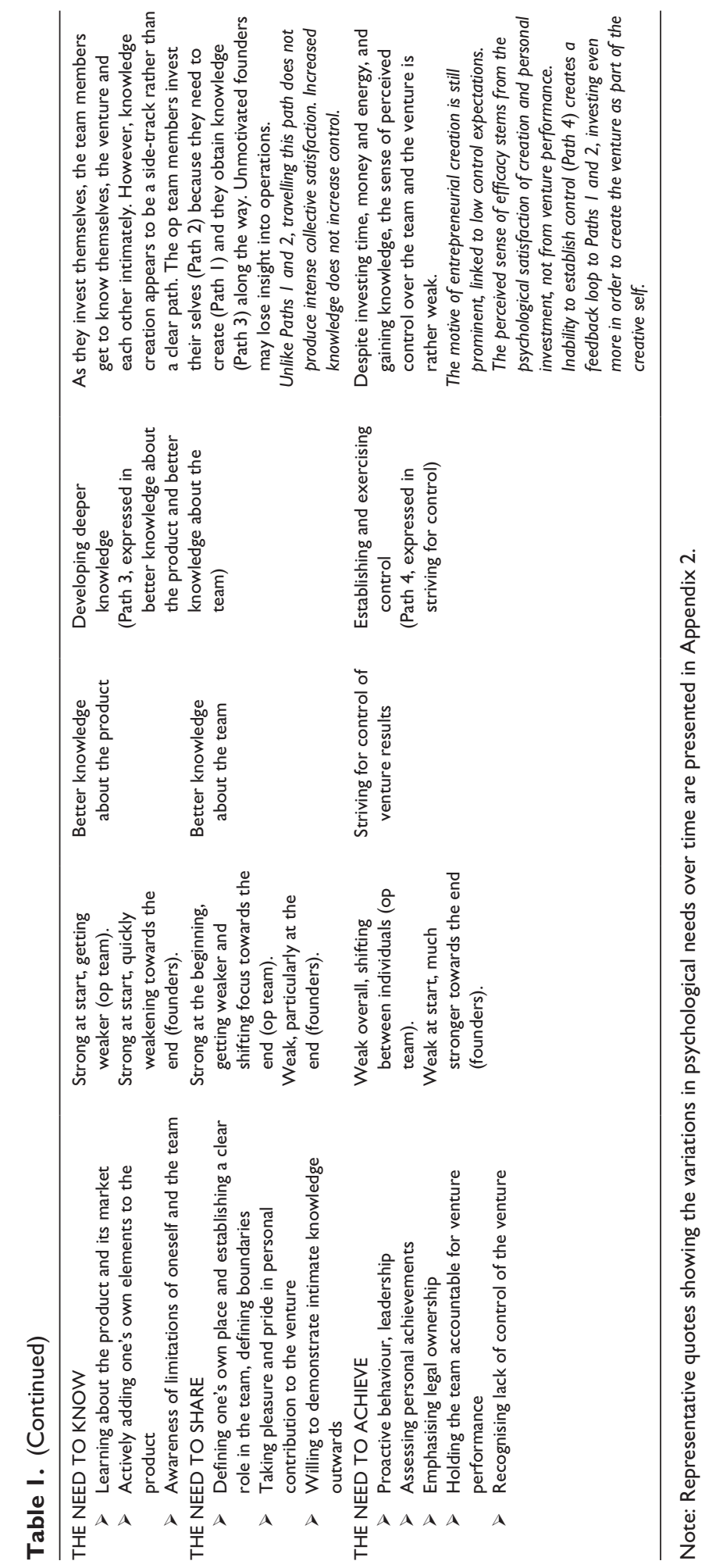




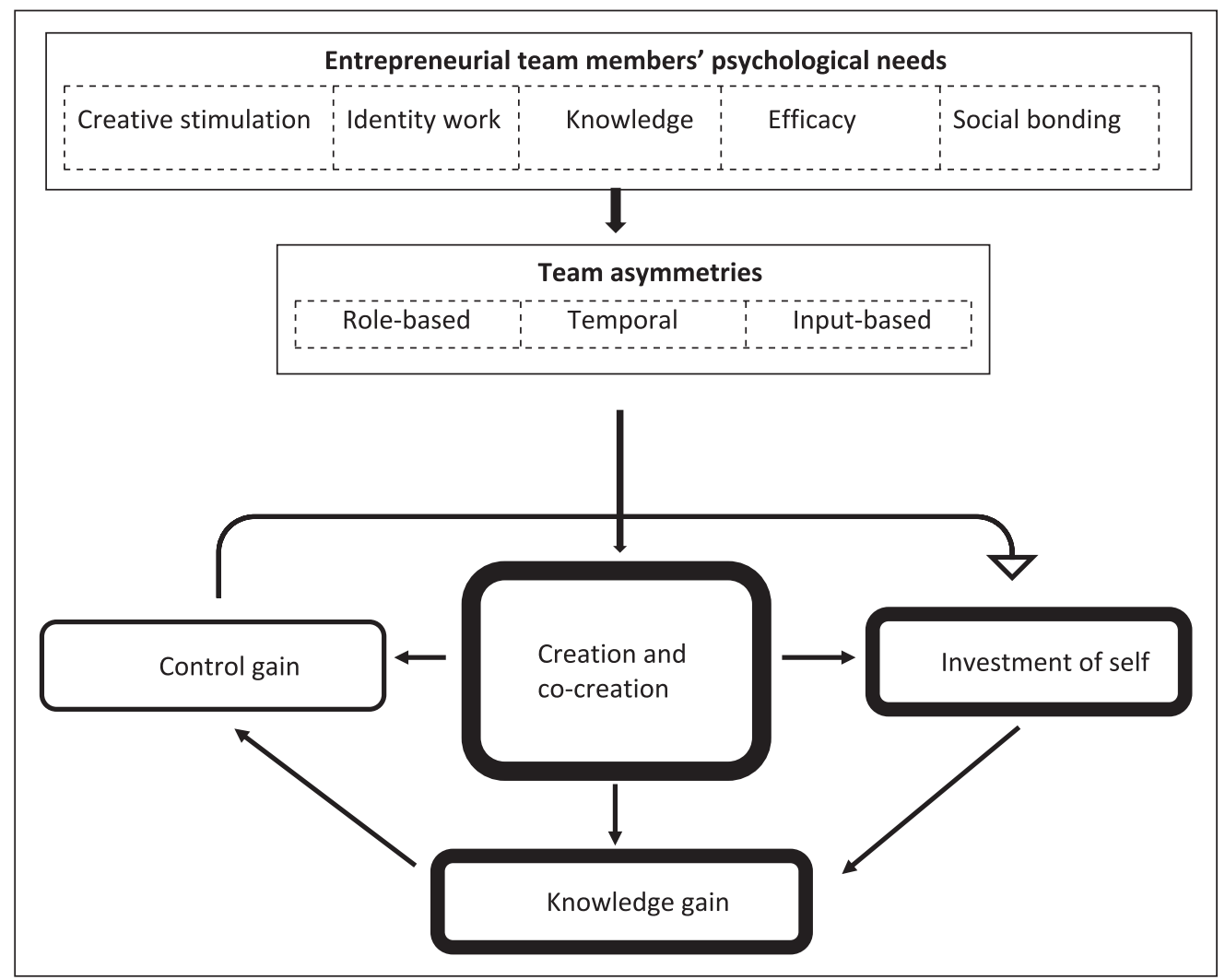

Figure I. Process of collective PO development in New Venture Teams.

PO: Psychological ownership.

at earlier and later stages of venture development. Foreshadowing our main findings, the process model in Figure 1 shows the interplay of the four paths towards collective PO development in NVTs, that emerged from the second-order themes in our longitudinal study. The figure highlights path of creation as a main driving force behind the process. Importantly, the model suggests that the four identified paths are inherently interlinked, and we visualise the complex path travel highlighting not only the needs and motivations of the entrepreneurs, but also asymmetries we have been able to identify as important in our understanding of the process as it unveils over time.

\section{The path of creation: creating the self, the team and the venture}

The overarching need to create and participate in creation emerges as a predominant motive in all the member descriptions of the NVT process. This need was expressed by team members from the very early stages of the venture process, and seemed to affect many of the other emotional expressions of needs, actions and experiences. As an op team member put it, 'Nothing can take this venture's place in my heart. I couldn't even think about it. It gives me such energy. It's like having a baby. Every time I get feedback from people on our product, it's a fantastic feeling'. In individual interviews, all team members repeatedly expressed a strong desire to create something on their own, frequently relating this need to their thoughts about themselves. 'I am always trying to be creative, 
in everything I do. I find immense joy in being here and being able to create my own things, together with other creative people', said one engineer, reflecting the feelings of other team members.

All team members expressed notions of innate entrepreneurial passion where they embraced creative opportunities in the risky entrepreneurial environment. Yet, as time went by, the founders expressed less enthusiasm about the creation of the entrepreneurial self. 'This is how I express my creativity; this is what keeps me going despite no success in sales. I knew what I was getting into. Quite a journey!' said an op team member in the later stages. Founders, meanwhile, demonstrated weaker creative urges, 'I was so passionate about it at the beginning, when I created the idea and the initial product. Now I have settled down. I know I have done my part', and 'I am excited to follow the progress from a distance now. There is no need for me to step in any longer'.

The founder or op member distinction, along with the temporal sequence of actions, can partly explain this asymmetry. While founders expressed themselves in the initial idea and its refinement, and took the first baby steps of venture creation, the op team gradually took over subsequent development. For the op team, this entrepreneurial identity work was such a predominant theme during the process that it affected the development of the whole venture - initially by being its major engine, and later leading to persistence in the face of poor performance, as an op team member explained,

I work all the time. I need to learn how to do things better and better. I put so much energy into this. It is the focus of my life now. None of us gets paid, and God knows how we can manage this, but I'm sure we will.

Our interviews also indicate that creative processes helped unite the team. At all development stages, we found that all of the op team members believed that the team was central to the venture, and even their own lives: 'We talk openly about being bold and innovative, pushing each other further and further. We want each other to succeed', and 'I am here because the team inspires me, and I know I can transform this into a beautiful product, so we all can benefit from this process', said op team engineers at the initial stages. Later, they confirmed that this feeling was just as strong in the final days of the venture. For the founders, the importance of creating a team was at its highest at the beginning of the process, diminishing along the way, mirroring the decline in the need to create the self: 'We founders gave the best boost to the team at the start, so the stakes are high for them now', said a founder at the later stages, while an op team member noted that 'We are proud of everything we have done. The op team is what this venture is about. The founders are supportive, but they left the creative part long ago'. This suggests an asymmetry in temporal focus on team creation; while the op team worked intensively on the creation of both their entrepreneurial and team identities, the creative contributions of founders did not endure.

Our data suggest that the emphasis by individual team member's creation of the self and the team came at the cost of a weak focus on the creation of the venture. The first verification stage revealed that the venture idea was attractive to customers, which gave a boost to the creative spirit of the team and confirmed their investment in creation. At later stages, the urge to create focused increasingly on the venture, especially as it became harder to get the desired recognition for creative efforts. 'The venture must be recognised, so we work actively on the practical side of things. The team is fine, but we need to raise awareness about our product, so that's what I do for all of us', said one op team member. Another op team member noted that, at the later stages,

I have done a lot to make this team work. We see ourselves as one unit. Times are harder now, but nobody gives up. If one of us gives up, the team won't be the same any more. I'm not sure there would be a team at all. And no team would mean the end of the venture.

This suggests that the team's increasing awareness of the inability to fully control the venture made the path of venture creation gradually more important than creating the entrepreneurial self. 
Furthermore, lack of timely collective focus on the venture might have contributed to weaker ownership feelings, despite the increased cohesiveness of the team.

The psychological needs described in this section focus on the need to create an entrepreneurial self, the need to create a team and the need to create a venture. We find that the strong desire to create and seek satisfaction from the development as a creative entrepreneur is central to the process of PO emergence. The inspiring opportunity to create an entrepreneurial self serves to strengthen the bonds between the entrepreneurial team members and the venture, making it an extension of their selves. This indicates the emergence of strong feelings of PO. Furthermore, we find that by being able to contribute to the creation of a joint vision, and maintain a collective spirit of creativity, entrepreneurial team members were able to satisfy their need to participate in creating a team. Here, team members found stimulation in having a collective sense of creating together, which enhances individual PO and provides a basis for the emergence of collective PO. We argue that PO emerges on both the individual and collective levels because team members travel the path of creation, where they establish their entrepreneurial identity. However, we find that asymmetrical input from different members into the process of creation may result in a failure to recognise and support creative efforts on a collective level. This asymmetry may lead to the satisfaction of individual needs and stronger individual PO, but weaker collective PO over time, since the collective need to create a venture is not satisfied for all team members. Importantly, we find that an increasing sense of PO correlates with an increasing desire to invest more of the self, which we identify as a second path towards PO.

\section{The path of investing time and energy into individual and collective identity work}

As team members invested time and energy with little or no remuneration, we found them seeking an entrepreneurial identity and defining themselves in the start-up environment. Recent college graduate members articulated this clearly in recurring interviews: 'I am trying to find myself here. I have no other experience and nothing to refer to, so this helps me understand what I can do', adding, 'If I could do more, I would, because I know I am investing in myself'. Everyone in the inexperienced op team demonstrated personal investment in the venture, and sacrifices for it. Recognition of achievements at the later stages of venture development indicated satisfaction and pride in their individual identity work: 'I have no doubt I have invested myself into this so much that I can call it mine. It's part of me now. I am myself when I work on this product'. All op team members expressed emerging feelings of ownership.

For the team, social relationships and informal rules of the game were shaped by the entrepreneurial passion everyone shared. As one op team member put it:

If I were to choose, I would put this company first in my life, no doubt, because the creative process here is irreplaceable. We learn a lot together, and I think it's key to our success that we share this attitude in the team.

The enthusiastic op team members said that finding joint interests and sharing visions contributed to the cohesiveness of the team and member wellbeing: 'The social part of our work is the most important. This is like a second home to us. I am happy to get here every morning and see [my teammates'] faces again'. This process, in turn, seems to have created strong identification with the venture, as another team member illustrated, 
I like doing this. To grow a firm from the start is lots of fun; it's my motivation. I like to create things from scratch [. . .] I have put a lot of work and commitment into this. But it's worth it. I am ready to go even further.

The collective dimension was vital for self-motivation and investment of time and energy of individuals: 'I see how much the others work, so I try even harder. We inspire each other. Everyone has offered an incredible amount now', an op team member explained. For the two founders, however, defining their own identity was not primarily attached to the venture. Investment of the self of founders was visible in the idea, the initial product and assembling the early-stage team. They delegated the maintenance of the joint team identity to the op team:

The op team is everything; there would be no venture without this team. I take my hat off to them. I do what I can to make sure they feel good. At the same time, I'm not of the same kind. I have a different life from them.

Thus, we discovered that asymmetry in the nature and amount of investment occurred on both individual and collective levels. This can be attributed to heterogeneity of team composition, as well as to venture progress over time.

Our interview data thus suggest that the path of investing the self is central to the creation of strong PO. In turn, the path of investment seems to be firmly related to the path of creation and participation in collective creative action. However, the asymmetry in the timing and amount of investment led to differences in the emerging PO between the founders and the op team, affecting the behavioural outcomes and attitudes of team members. The feeling of unequal investment caused palpable friction. The op team members continued to invest themselves in creation of collective identity, even in times of hardship. In contrast, at the later stages, a founder said,

I know what I am in this team. I gave birth to the idea in the first place! God knows how much effort I put into this before the team arrived. Well, you may say they have compensated for that now, but I don't think you can compensate for the idea. So, what is worth more: time spent on practical work, or the idea? You can find people, but you cannot find an idea.

Another founder noted, 'This company works on my product, but it's not like it's part of me. I haven't lived and breathed it every day like they did'. This suggests that while investment on a personal level produced increased feelings of possession of the venture, the asymmetry of personal investment hampered the growth of strong collective PO.

We identify the psychological needs described in this section as the need to define the self, the need to act and the need to share meaning and identification. Here, we find that entrepreneurs engage in individual identity work by investing their time, money and energy, and even making personal sacrifices in order to realise their creative potential. We find that the path of investing the self is prominent in every team member's journey towards PO. Since investing into self-definition helps to satisfy entrepreneurial needs, this path triggers even greater investment in the journey. This shows that there is a correlation between the path of investment and the path of creation, which indicates that travelling both of these paths is essential for strong feelings of PO to arise.

Indeed, our data suggest that the need to act reflects various kinds of input that team members bring to the process. Feelings of being consumed and obsessed by work correlate with the joy of gaining a new understanding of the self and the venture. Furthermore, we find that the need to share meaning and identification is also part of the force that drives investments into the venture, which indicates that entrepreneurs travel the path of investing collectively. By sharing the work and 
sharing a belief in the importance of entrepreneurial action, they satisfy their collective need to share meaning and identification and engage in joint identity work where the venture becomes part of a collective self. This indicates that collective travel along the path of investment leads to stronger collective PO. Yet, we find that investments of different kinds - and, importantly, at different stages of venture development - may weaken a sense of collective PO despite an increasingly strong sense of individual PO. Our case demonstrates how temporal and input-based asymmetries affect the joint experience of travelling this path. Furthermore, we find that while investment increases knowledge, it does not generate a sense of control and efficacy. We discuss these findings in detail below.

\section{The path of knowledge development}

The path of personal investment emerges in our analysis as linked to a need for deeper knowledge of three elements: the product, the team and the venture. Op team members all emphasised that they had to master hardware, software, sales and administration in detail, with less support from founders. 'I am constantly developing myself, learning more about all kinds of things, both in engineering and businesswise', said one team member. 'It's like a sweet poison; it's good'. He later confirmed,

This is fascinating. I can really tell this is MY company because I have been there for the whole process. I am proud to say I have all the knowledge about this product, from the bottom to the top, inside and out. I don't think I am easy to replace, with everything I know about the product and the team.

Notably, the focus on knowing the product diminished in significance for both op team members and founders as the venture progressed. Rather, increased knowledge seems to have enhanced confidence and feelings of establishing a member's identity as a 'competent engineer' or 'entrepreneur'. 'I have grown so much, I could design anything', said one team member. 'I'm really up to creative challenges now'.

Team members often emphasised that getting to know each other was just as important as getting to know the product. The op team worked very informally, especially at the initial stages, focusing on creating collective knowledge and making a social contribution to the team. As a founder put it, 'We know what everybody stands for in the team. Everyone knows what they are doing, and we see each other's achievements clearly. This knowledge is important for the op team; they are new to entrepreneurship'. Our data suggest that the members travelled the path of gaining individual and collective knowledge as part of the process of creating team identity. The idea of creating something new together united the op team and the founders, as an op team member notes,

Everybody works on their personal task, but there is no value in fixed positions. We take care of things for each other and make sure to keep it running. You can show your best self by finding new ways, new solutions, being creative together.

At later stages, team-based collective knowledge led to higher self-esteem and deeper understanding of the entrepreneurial self for them. 'I feel much more comfortable here now; I know what I stand for and I know how this company works, so I am not afraid to speak up at all', an op team member said, while others expressed similar feelings.

The data reveal that intimate knowledge of the product, the self and the team are tightly interlinked. We can also see how the different paths towards feelings of possession are interrelated. Travelling the path of heavy investment over a long period may lead to increased knowledge, which in turn can be expressed in closer attachment to the venture. As they continuously travel 
down the path of creation, team members form their entrepreneurial identity with enhanced feelings of the venture as part of themselves.

However, knowledge asymmetry may complicate the journey. The founders relied on ability of individual op team members to develop their own skills and knowledge, considering the team's overall lack of business skills: 'It's a very good team, no doubt', said one founder. 'I wish I could have done more for them, but I knew I couldn't. So they stalled'. The other founder added, 'I told them early on that we needed more salespeople. Now we see the result-we hardly have a venture left'. The poor performance at later stages was explained by the shortage of relevant competence and experience in the op team, plus a lack of clear leadership. Despite an intense learning experience, the op team could not control the venture. An op team member explained,

Often, I am hesitant because I feel I don't have the facts, or the knowledge of what to do with the venture. I am fully aware of that, and it makes me uncomfortable. We all know we don't have anybody to tell us what's right or wrong.

The inability to improve venture performance made the op team realise their knowledge limitations at later stages, while persisting with the venture. Both the op team and the founders continued to invest their time and energy in the venture, engaging in sales efforts without drawing a salary.

Our findings highlight two psychological needs of team members. The need to obtain deeper knowledge about the product and that the venture drives entrepreneurs to work actively on the product, learn more and experiment. This process gives them a feeling of pride and satisfaction in their own knowledge and their ability to realise their own potential by acquiring expertise. Interestingly, our data suggest that while knowledge increase may produce feelings of 'my' venture, the knowledge base involved is narrow and specific to each person, being based on their roles and assignments in the team. We find that entrepreneurs exhibit a collective need to seek each other's support in learning and sharing knowledge, as well as in confirming each other's expertise and contribution. This is particularly oriented towards teamwork for those members who joined the team later. While this leads to the emergence of collective PO, this feeling does not seem to grow stronger as knowledge increases. This could be explained by an asymmetrical knowledge base and differences in when knowledge is acquired. We find that despite investing time, money and energy, and getting knowledge, sense of achievement is weak, indicates that this path does not lead to an increased sense of collective PO.

\section{The path towards greater control and efficacy}

All team members expressed weak perceived control of the venture throughout the study period. The increasing passivity of the founders triggered the need for more control, prompting op team members to follow the path towards control and change their working pattern. Joint decisionmaking was stressed as a symbol of joint creativity, seemingly contributing to feelings of individual and joint control. Yet, at later stages an op team member described how this changed, mirroring feelings of the other op team members:

I know what this product can and cannot do. I can explain it to the team and to the customers, but this is not about me. I guess none of us can really account for everything here; this feeling has grown upon us.

Despite having travelled the paths of heavy investment and increased knowledge, all the team members realised they could not take full control of the venture as a business unit. At later stages, the op team came to see themselves as founders, and claimed more control, once they had travelled the path of creation together. As one of them explained, 
All of us in the operational team are founders, I'd say now. Sure, the original idea came from one of the founders, so his spirit needs to permeate our work, to some degree. But I believe that all of us are the driving spirits of this venture now - especially the ones who joined quite early.

This feeling gave them confidence in having created a secure home where they could continue developing their entrepreneurial selves. One of the founders described his role as 'indirect control' that remained from the initial stages:

The short answer is I don't do much anymore. I have technical skills, so I can be a critical voice in technical questions. [But] in practice, I don't have time. We founders contributed enough during the preparations. We have made it clear from the start that we are owners, but we cannot be around so much for the operative phase.

This highlights how the op team's increasing sense of control balances the diminishing control of the founders, while both groups acknowledge the limits of their control in the context of entrepreneurial uncertainty. Yet, legal ownership may not lead to an increased sense of control if the team travels the paths to PO asymmetrically. In our study, op team members demanded, and received, more ownership shares in return for their efforts. This increased the op team's feeling of control and ownership of the venture, both individually and collectively. An op team member expressed both individual and collective feelings:

I have got more shares from the founders now; it gives me energy. I feel that this, in fact, is MY company. I am building this, so it's mine. You see what I mean? Each one of us owns this. Everybody works in the company. No matter what they say, it's OUR company.

At the same time, all members explained that the shares had a mere symbolic meaning, interpreted in terms of collective identity and cohesiveness rather than actual control over venture performance. Poor tangible performance at later stages made both the op team and the founders rethink their journey and consider whether to continue despite team attachment after having travelled the paths together, as an op team member confirms,

We are at a critical point, but there is no plan. If nothing happens and we go on as usual, having fun at work and so on, it's clear we will have no company in a few months. I wonder if we'll manage to keep up the team spirit.

This section highlights the psychological need to achieve results, which must be satisfied in order to enhance the sense of PO. We find that the path of establishing and exercising control is pivotal to the development of collective PO. Our data suggest that along the path of gaining control, the established feeling of joint ownership leads to persistence among the team, even in the face of failure. Entrepreneurial identity journeys of individuals can thus enhance joint team identity and increase cohesion. However, this is not sufficient to achieve results, gain control of the venture and produce a strong sense of efficacy. The inability to control venture performance, both individually and collectively, produces feelings of detachment, since the venture is not perceived as part of the self. Therefore, the sense of collective PO may not be strengthened by travelling this path. Again, we argue that the role-based, input-based and temporal asymmetries that have influenced the four paths have a key explanation. Rather, failures may contribute to insecurity about the self and one's entrepreneurial identity, which, in turn, may weaken one's individual PO.

Our findings thus indicate how and why the team members travelled the four identified paths towards PO. We continue our data analysis by discussing the interplay of the paths as well as the 
asymmetries we identified at different stages of the journey, which seem to have hampered the development of collective PO.

\section{Path interplay and the role of asymmetries in collective PO development}

Our case study highlights the new venture as a target that must meet entrepreneurial needs, which, in turn, triggers an entrepreneurial journey down the entrepreneurial path of creation that has not previously been recognised in PO literature. In NVTs, the need for creative stimulation is the central driving factor that directs the team member actions and behaviours. Joining the entrepreneurial path of creation and co-creation, the entrepreneurs are united in the desire to make both individual and collective contributions to the venture. We find that this path constitutes the foundation for the whole journey, activating the mechanisms that prompt entrepreneurs to travel the other three paths.

During the three initial years of the venture, the team ultimately failed to reach major milestones such as establishing a customer base, verifying sales and attracting any sizable investment. Despite the asymmetrical journey and the unsatisfactory venture development, the team has demonstrated persistence and desire to continue working together, finding an overwhelming joy in the experience of joint creation and the formation of joint entrepreneurial identity. Our analysis shows that lack of perceived joint control in an entrepreneurial context may trigger a team to extend creative identity work, invest in the self and further create and co-create, and, thus, gain more knowledge and a greater sense of identification with, and ownership of, the venture (Figure 1).

Our analysis also suggests that lack of control over venture performance is reflected in lower confidence in one's entrepreneurial capabilities and efficacy. Yet, weak control does not seem to hamper entrepreneurial efforts. The urge for creation is identified as a central process of PO development in our study, where recurring elements of creation are present in all four paths in Figure 1. All individuals in our study apparently travelled these paths, and data indicate that all active team members developed a strong sense of individual PO. 'This venture is part of me now' and 'This is definitely my venture' were frequent highlights of the importance of their psychological attachment.

However, collective PO did not emerge as unifyingly strong. Our analysis suggests that sharing experiences during the venture journey is important to an NVT, as such shared experiences boost collective feelings of belonging, active contribution and both individual and collective entrepreneurial identity. We identify collective identity work as the central driving force towards collective PO. However, recurring lack of control over the venture may taint the psychological benefits of working together and affect ownership feelings. Furthermore, if the founders and the op team travel the paths at different speeds and with different goals, they neither share the same experiences nor gain a collective sense of identification with the venture. The extent to which an NVT travels the paths collectively or individually is, therefore, highlighted as a focal issue in the process model. United by a joint psychological need to participate in creation, the whole venture team in our study travelled the dominant and gratifying path of creation for a long period, demonstrating strong entrepreneurial persistence even in adversity. Such centripetal forces may be needed to keep the team members together, since they adhere to both individual creative needs and social needs, providing processual interconnectedness (Sklaveniti, 2017) and enabling the collective journey along the path (Gray et al., 2019).

As highlighted, temporal and role-based asymmetries between the founders and the op team members led to weaknesses in the studied team. Furthermore, our data contrast the op team's increased psychological engagement with the founders increased psychological disengagement (Rouse, 2016), suggesting that the amount and intensity of the input of different members create challenges for collective PO development. Asymmetries in the paths to collective PO may thus weaken the feeling of collective ownership of the venture, even if each individual travels the paths 
to individual ownership, as highlighted in our process model. This suggests a plausible explanation for the relative 'strength of emergence' of PO highlighted as central issue in research on emergent states (Waller et al., 2016), by demonstrating the mechanisms where an emergent state arises from lower level dynamics within the team, in turn affecting individual behaviours.

While our findings highlight the paths to PO as ostensive (experienced by team members) and coherent (enduring over time), a central contribution of our process model is to explain why teams may develop potentially rather weak collective PO, even in the presence of strong individual PO (Pierce et al., 2003; Pierce and Jussila, 2010), since we find the pattern of PO emergence to be both enduring and varying across the team (Waller et al., 2016). While extant models of collective PO assume it to emerge naturally as a result of strong individual PO, our study highlights that strong individual PO is not sufficient. Our data suggest that a strong sense of collective PO requires continuously shared experiences and continuously consistent sets of values shared by both founders and team members. Furthermore, an inability to meet the need for joint control undermines the strength of emergence on the collective level, reducing its coherence and undermining assumptions of 'emergent state omnipresence' (Waller et al., 2016: 586). Thus, our process model explains how strong and weak emergence can coexist on different levels. These findings shed further light on the interplay of the four paths towards both individual and collective PO, going beyond previous theorising on PO (Pierce and Jussila, 2011; Van Dyne and Pierce, 2004). We identify the path of creation and, importantly, co-creation as central to our theoretical understanding of collective PO and its emergence in a disruptive new venture context. We argue that the discrepancy between individual and collective PO, as well as the interplay between the paths, may be central to our understanding of NVT processes and NVT performance.

Our analysis highlights how acts of investing the self need not be oriented towards gaining enhanced control (Liu et al., 2012), but rather at creative self-identity of members, meaning that the time, effort and personal sacrifices spent on behalf of the venture affect identity of individuals as creators and entrepreneurs (Grimes, 2018). Personal identification through investment of the self is also reflected in the patterns of emerging engagement and disengagement in the team (Rouse, 2016). Such processes of entrepreneurial identity construction emerge as a precursor to PO in our study, highlighting how the self-efficacy of team members is shaped by enhancing their perceived knowledge and familiarity with the venture and its artefacts, such as hardware and software development. The timing and amount of personal investment appear as two crucial factors in determining the psychological value of investment and the strength of PO over time. In contrast to studies of PO in established organisations, we could not confirm that a feeling of PO among either the op team or the founders primarily stemmed from having increased control (efficacy) over the venture (Dawkins et al., 2017). Rather, our findings suggest that individuals develop a sense of increased control of the self, because of ongoing creative identity work (Leitch and Harrison, 2016). For the team, this becomes a question of control over venture performance, as well as team performance.

In sum, our process model draws attention to the importance of symmetrical experiences of entrepreneurial teams in travelling the paths towards collective PO. Our analysis of the needs of team members, both similar and different, explains the causes and contextual implications for these on both the individual and collective levels.

\section{Discussion and conclusions}

Following all members of a NVT during its early development allowed us to document and analyse the motivational triggers and processes by which NVT members developed a sense of PO of the venture. In doing so, we inductively generated a process model explaining collective PO as an 'emergent state' in NVTs, where individual PO feelings are necessary, but not sufficient, conditions 
for the emergence of collective PO. While some universal needs for individual PO in new ventures follow from extant theory, our findings suggest that individual differences in terms of career background, previous experiences and expectations may lead to different needs, prompting NVT members to travel four different paths at various points in time. This can lead to different behavioural manifestations of individual PO, as well the team failing to develop a strong sense of collective PO. Our study and tentative process model contributes to the literature on NVTs, which, despite burgeoning research, has so far said relatively little about interpersonal processes in NVT development (Davidsson and Gordon, 2012; Hjorth et al., 2015; Klotz et al., 2014). We also contribute to research on PO emergence, which to date has primarily studied sole individuals in established organisations, and assumed that paths to individual and collective PO are symmetrical (Pierce and Jussila, 2011). We suggest that strong collective PO emerges not as a sum of individual feelings and experiences, but rather as the result of a process where asymmetries affect the emergence of shared feelings of ownership. In particular, we show that despite the joy of co-creation, the asymmetrically shared investment of the self and asymmetrical collective knowledge, produce a feeling of weak joint efficacy, resulting in weak collective PO.

\section{Contributions to research on NVTs}

Our study identifies preconditions for PO development in NVTs that enhance our understanding of the importance of team composition at the initial stage, and role-based changes as the venture matures. We identify these preconditions as psychological needs for belonging, knowledge, control and entrepreneurial creation. We also highlight the importance of temporal symmetry in complex interpersonal processes aimed at meeting these needs, contributing rare knowledge of the processes leading to emergent states in NVTs (Ben-Hafaïedh, 2017; Klotz et al., 2014). Our findings suggest that the affective emergent state of PO may play a major part in the collective input of effort and resources to the new venture, highlighting the social processes involving temporal dynamics and complex causal mechanisms in emergent states (Waller et al., 2016) and focusing on nuances of co-action and co-creation (Sklaveniti, 2017). Specifically, strong individual PO but weak collective PO may be key to an enhanced understanding of why creative teams can stay intact for so long despite failing to reach important milestones and enduring personal hardships. These findings inform the familiar scenario in which some entrepreneurial teams 'hang on for too long' despite poor performance, challenging earlier research attributing such escalation of commitment to overconfidence or lack of external opportunities (Gimeno et al., 1997; McMullen and Kier, 2016). Emotional aspects such as a feeling of belonging and the joy of creativity may well outshine limits in efficacy and actual progress in NVTs, meaning that those who do 'hang on for too long' need not necessarily be overconfident or lack external opportunities. While we cannot explicitly link weak feelings of collective PO in our case to the venture's poor performance, we note that pattern of weak emergence did contribute to diminishing enthusiasm, growing disengagement and weakening joint focus on the venture, factors argued to be central for 'productive emotions' and entrepreneurial motivation in new ventures (Cardon et al., 2017). These findings provide input to the problematisation of entrepreneurial failure (Nummela et al., 2016). While insights gleaned from this article are limited to a single longitudinal case study, the study is to the best of our knowledge the first to attend to the implications of role-based, input-based and temporal symmetry for the development of collective PO. The proposed process model suggests that collective PO in new ventures can manifest itself differently due to the identified asymmetries, provides fertile ground for further process-related research on entrepreneurial team building and social embeddedness in entrepreneurship (Cooney, 2005; Dodd and Anderson, 2007), as well as emergent states in NVTs, such as leadership emergence and interpersonal trust. 


\section{Contributions to research on psychological ownership}

Our proposed process model of PO development in NVTs suggests that an overarching psychological need for creation is central to the entrepreneurial path towards PO. Our model stresses that for creative and self-organising settings such as entrepreneurship, an important path for collective PO development is the path of creation. This path is not considered in previous literature on PO, yet we find it to be central to the NVT context. In a turbulent start-up environment, joint creation can bring everyone together despite their diverse backgrounds and psychological needs - founders and team members alike (Powell and Baker, 2017). As our longitudinal case study suggests, creation is what connects the other paths, providing them with a direction and a joint focus, especially when it proves difficult to travel the path of increased control and efficacy.

Research on PO in established organisations assumes that a sense of collective PO will emerge if individuals travel all, or at least many, of the paths together (Pierce and Jussila, 2011). Our findings contrast this assumption, stressing that individual and collective PO develop asymmetrically and depend on member or role composition, personal needs and, importantly, temporal issues. Answering the heed for longitudinal process-oriented studies on individual and collective PO (Dawkins et al., 2017) in specific contexts (Ikävalko et al., 2010), we focus on PO emergence at both the individual and team levels in an NVT context. Our case study reveals patterns of emergence as an interplay of four paths over time, resulting in a process model that indicates that these patterns may be contingent on a number of asymmetries. Such asymmetries have not yet been addressed in the PO literature, but provide interesting avenues for further research on PO in an entrepreneurship setting. For example, further research is needed to gauge whether asymmetries related to individual role and input differences in the team are more or less central to team-level emergent states. Also, the interplay of the paths towards PO may be further scrutinised to shed more light on the creation of joint entrepreneurial identity in teams, as well as processes of creation and co-creation in entrepreneurship.

\section{Transferability of findings}

Lacking a comparative case exhibiting strong collective PO, a natural counterfactual question is whether the asymmetries we identify should be eliminated in NVTs. While variation in member roles and needs does seem to contribute to these asymmetries, one should remember that NVTs are often built on the idea of team heterogeneity and social interplay (Cooney, 2005; Klotz et al., 2014) with the potential for conflict (Kozlowski and Ilgen, 2006). This question is inherently linked to our discussion on strong and weak emergence with teams considered as 'strong emergence' domains (Waller et al., 2016), highlighting time as a crucial ingredient in explaining the asymmetries that result in both strong and weak patterns of emergence on different levels in an entrepreneurial context. A fully symmetrical process characterised by conformity in both member roles and needs, as well as process experience, could well create stronger collective PO. Whether this would also mean poorer variability of idea generation, and potential for groupthink, represents an important avenue for future research.

\section{Limitations and future research}

While single case study data come with limitations in empirical generalisability, our study and process model provide theoretical implications that further research can assess for analytical generalisability. One limitation is that technology, local legislation, financial preconditions and 
cultural factors may affect collective PO differently, with financial conditions and formal ownership structure being more or less important for collective PO. Similarly, collective PO emergence could well occur differently across high-trust and low-trust cultural contexts (Welter, 2012). Future research could examine the contextual nature of PO in general and contexts of NVTs in particular, as well as the constituent elements and attributes of each path and their significance for PO. Specifically, our finding that participating in creation contributes to team member development of collective PO echoes Grimes' (2018) study of the PO of individual entrepreneurs, which could be further extended by social-psychological studies of creativity or passion in entrepreneurial teams (Cardon et al., 2017; Collewaert et al., 2016). Furthermore, our process model explains how the timing and continuity of active membership may be important for NVT development, which motivates research on social dynamics behind changes in entrepreneurial motivation as well as the reasons behind disengagement (Rouse, 2016). Finally, comparative work is needed to probe the generality of our process model and tease out the nuances through which team member psychological heterogeneity affects the development of collective PO.

\section{Conclusion}

Our longitudinal study explores the complex interplay of the paths towards collective PO in NVTs. We highlight asymmetries in the process of co-action and co-creation and discuss the importance of temporal, role-based and input-based alignment of interpersonal processes in the multi-level pattern of emergence of collective PO in NVTs. Our model provides a processed-oriented framework for understanding entrepreneurial team interaction in time, enabling a deeper understanding of the development of emergent states in entrepreneurship.

\section{Acknowledgements}

The authors are grateful for comments from Anna Brattström, Frederic Delmar, Sarah Jack, Tomas Karlsson, Alan Johnson, Pamela Novell, Karen Williams Middleton and seminar participants at the 2018 Nordic Conference on Small Businesses (NCSB), the 2019 European Academy of Management Meeting (EURAM) in Lisbon and the 2019 Academy of Management Meeting in Boston, and especially to the editor and two referees. All errors remain those of the authors.

\section{Funding}

The author(s) disclosed receipt of the following financial support for the research, authorship and/or publication of this article: Our research was financially supported by the Ragnar Söderberg Foundation and Handelsbanken Research Foundations.

\section{ORCID iD}

Karl Wennberg (iD) https://orcid.org/0000-0001-7279-1006

\section{Notes}

1. PO differs from other forms of organisational attachment, commitment and work-related attitudes in having unique and identifiable motivations, mechanisms, manifestations and consequences (Pierce and Jussila, 2011). Here, we outline the key building blocks of the PO concept on the individual and collective levels, highlighting the unexplored emergent state of $P O$, its manifestations and its possible outcomes in the NVT context, where founders and team members travel the paths to feelings of venture ownership.

2. A detailed overview of our data, sources and informants can be found in Appendix 1. 


\section{References}

Alper S, Tjosvold D and Law K (1998) Interdependence and controversy in group decision making: Antecedents to effective self-managing teams. Organizational Behavior and Human Decision Processes 74: $33-52$.

Avey J, Avolio B, Crossley B, et al. (2009) Psychological ownership: Theoretical extensions, measurement and relation to work outcomes. Journal of Organizational Behavior 30: 173-191.

Bandura A (1997) Self-efficacy: The Exercise of Control. Basingstoke: W. H. Freeman.

Ben-Hafaïedh C (2017) Entrepreneurial teams research in movement. In: Ben-Hafaïedh C and Cooney TM (eds) Research Handbook on Entrepreneurial Teams. Cheltenham: Edward Elgar, pp.11-44.

Bjornali E, Knockaert M, Foss N, et al. (2017) Unraveling the black box of new venture team processes. In: Ahmetoglu G, Chamorro-Premuzic T, Klinger B, et al. (eds) Wiley Handbook of Entrepreneurship. Hoboken, NJ: John Wiley, pp.313-348.

Breugst N, Patzelt H and Rathgeber P (2015) How should we divide the pie? Equity distribution and its impact on entrepreneurial teams. Journal of Business Venturing 30: 66-94.

Cardon M, Post C and Forster W (2017) Team entrepreneurial passion: Its emergence and influence in new venture teams. Academy of Management Review 42: 283-305.

Collewaert V, Anseel F, Crommelinck M, et al. (2016) When passion fades: Disentangling the temporal dynamics of entrepreneurial passion for founding. Journal of Management Studies 53: 966-995.

Cooney T (2005) What is an entrepreneurial team? International Small Business Journal 23(3): 226-235.

Davidsson P and Gordon S (2012) Panel studies of new venture creation: A review and suggestions for future research. Small Business Economics 39: 853-876.

Dawkins S, Tian A, Newman A, et al. (2017) Psychological ownership: A review and research agenda. Journal of Organizational Behavior 38: 163-183.

Dodd DS and Anderson AR (2007) Mumpsimus and the mything of the individualistic entrepreneur. International Small Business Journal 25(4): 341-360.

Gimeno J, Folta T, Cooper A, et al. (1997) Survival of the fittest? Entrepreneurial human capital and the persistence of underperforming firms. Administrative Science Quarterly 42: 750-783.

Gioia D, Corley K and Hamilton A (2013) Seeking qualitative rigor in inductive research: Notes on the Gioia methodology. Organizational Research Methods 16: 15-31.

Gray S, Knight A and Baer M (2019) On the emergence of collective psychological ownership in new creative teams. Organization Science 31(1): 141-164.

Grimes M (2018) The pivot: How founders respond to feedback through idea and identity work. Academy of Management Journal 61: 1692-1717.

Hjorth D, Holt R and Steyaert C (2015) Entrepreneurship and process studies. International Small Business Journal 33: 599-611.

Ikävalko M, Pihkala T and Kraus S (2010) The role of owner-managers' psychological ownership in SME strategic behaviour. Journal of Small Business \& Entrepreneurship 23: 461-479.

Klotz A, Hmieleski K, Bradley B, et al. (2014) New venture teams: A review and roadmap for future research. Journal of Management 40: 226-255.

Kozlowski S and Ilgen D (2006) Enhancing the effectiveness of work groups and teams. Psychological Science in the Public Interest 7: 77-124.

Leitch C and Harrison R (2016) Identity, identity formation and identity work in entrepreneurship: Conceptual developments and empirical applications. Entrepreneurship \& Regional Development 28: 177-190.

Liu J, Wang H, Hui C, et al. (2012) Psychological ownership: How having control matters. Journal of Management Studies 49: 869-895.

McMullen J and Dimov D (2013) Time and the entrepreneurial journey: The problems and promise of studying entrepreneurship as a process. Journal of Management Studies 50: 1481-1512.

McMullen J and Kier A (2016) Trapped by the entrepreneurial mindset: Opportunity seeking and escalation of commitment in the Mount Everest disaster. Journal of Business Venturing 31: 663-686.

Marks M, Mathieu J and Zaccaro S (2001) A temporally based framework and taxonomy of team processes. Academy of Management Review 26: 356-376. 
Mathieu J, Maynard M, Rapp T, et al. (2008) Team effectiveness 1997-2007: A review of recent advancements and a glimpse into the future. Journal of Management 34: 410-476.

Mayhew M, Ashkanasy N, Bramble T, et al. (2007) A study of the antecedents and consequences of psychological ownership in organizational settings. The Journal of Social Psychology 147: 477-500.

Neergaard H and Ulhøi J (2007) Handbook of Qualitative Research Methods in Entrepreneurship. Cheltenham: Edward Elgar.

Nummela N, Saarenketo S and Loane S (2016) The dynamics of failure in international new ventures: A case study of Finnish and Irish software companies. International Small Business Journal 34(1): 51-69.

Orton J (1997) From inductive to iterative grounded theory. Scandinavian Journal of Management 13: 419438.

Packard M, Clark B and Klein P (2017) Uncertainty types and transitions in the entrepreneurial process. Organization Science 28: 840-856.

Pierce JL and Jussila I (2010) Collective psychological ownership within the work and organizational context: Construct introduction and elaboration. Journal of Organizational Behavior 31: 810-834.

Pierce JL and Jussila I (2011) Psychological Ownership and the Organizational Context: Theory, Research Evidence, and Application. Cheltenham: Edward Elgar.

Pierce JL, Kostova T and Dirks K (2001) Toward a theory of psychological ownership in organizations. Academy of Management Review 26: 298-310.

Pierce JL, Kostova T and Dirks K (2003) The state of psychological ownership: Integrating and extending a century of research. Review of General Psychology 7: 84-107.

Pittino D, Martínez A, Chirico F, et al. (2018) Psychological ownership, knowledge sharing and entrepreneurial orientation in family firms. Journal of Business Research 84: 312-326.

Powell E and Baker T (2017) Identity processes and organizing in multi-founder nascent ventures. Academy of Management Journal 60: 2381-2414.

Rouse E (2016) Beginning's end: How founders psychologically disengage from their organizations. Academy of Management Journal 59: 1605-1629.

Siggelkow N (2007) Persuasion with case studies. Academy of Management Journal 50: 20-24.

Sklaveniti C (2017) Processes of entrepreneurial leadership: Co-acting creativity and direction in the emergence of new SME ventures. International Small Business Journal 35(2): 197-213.

Van Dyne L and Pierce J (2004) Psychological ownership and feelings of possession: Three field studies predicting employee attitudes and organizational citizenship behavior. Journal of Organizational Behavior 25: 439-459.

Waller M, Okhuysen G and Saghafian M (2016) Conceptualizing emergent states: A strategy to advance the study of group dynamics. Academy of Management Annals 10: 561-598.

Wasserman N (2017) The throne vs. the kingdom: Founder control and value creation in startups. Strategic Management Journal 38: 255-277.

Welter F (2012) All you need is trust? A critical review of the trust and entrepreneurship literature. International Small Business Journal 30(3): 193-212.

Yin R (1989) Case Study Research: Design and Methods (ed DT Campbell, 2nd edn, Applied Social Research Methods). Newbury Park, CA: Sage.

Zhu H, Chen C, Li X, et al. (2013) From personal relationship to psychological ownership: The importance of manager-owner relationship closeness in family businesses. Management and Organization Review 9: $295-318$.

\section{Author biographies}

Olga Yttermyr is a Senior Lecturer in Business Administration at Linköping University, Sweden. Her research focuses on organizational processes, longitudinal case studies and hybrid forms of organizing.

Karl Wennberg is Professor in Business Administration at Stockholm School of Economics, Sweden. His research focuses on entrepreneurship, organizations, and education. 


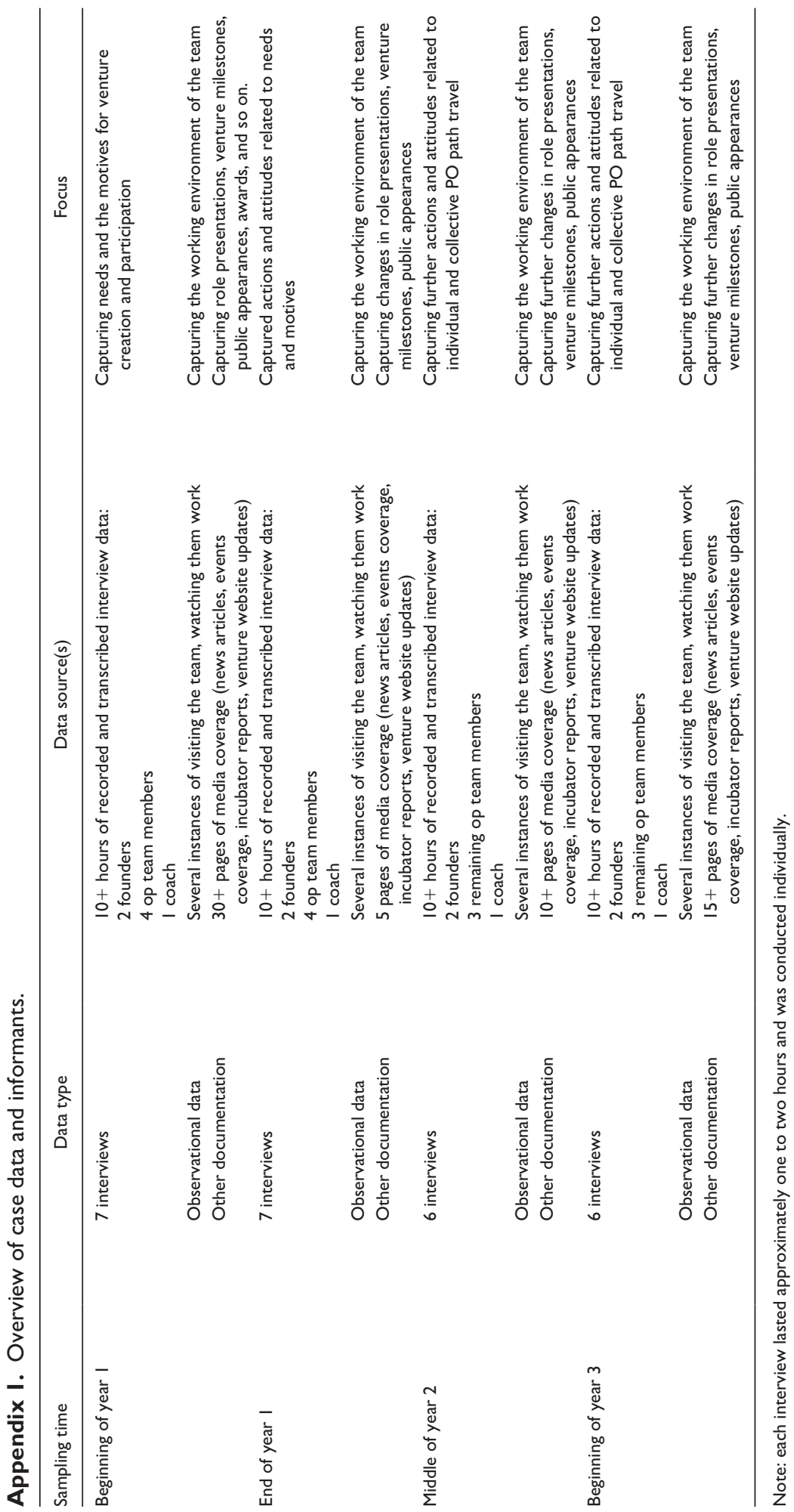




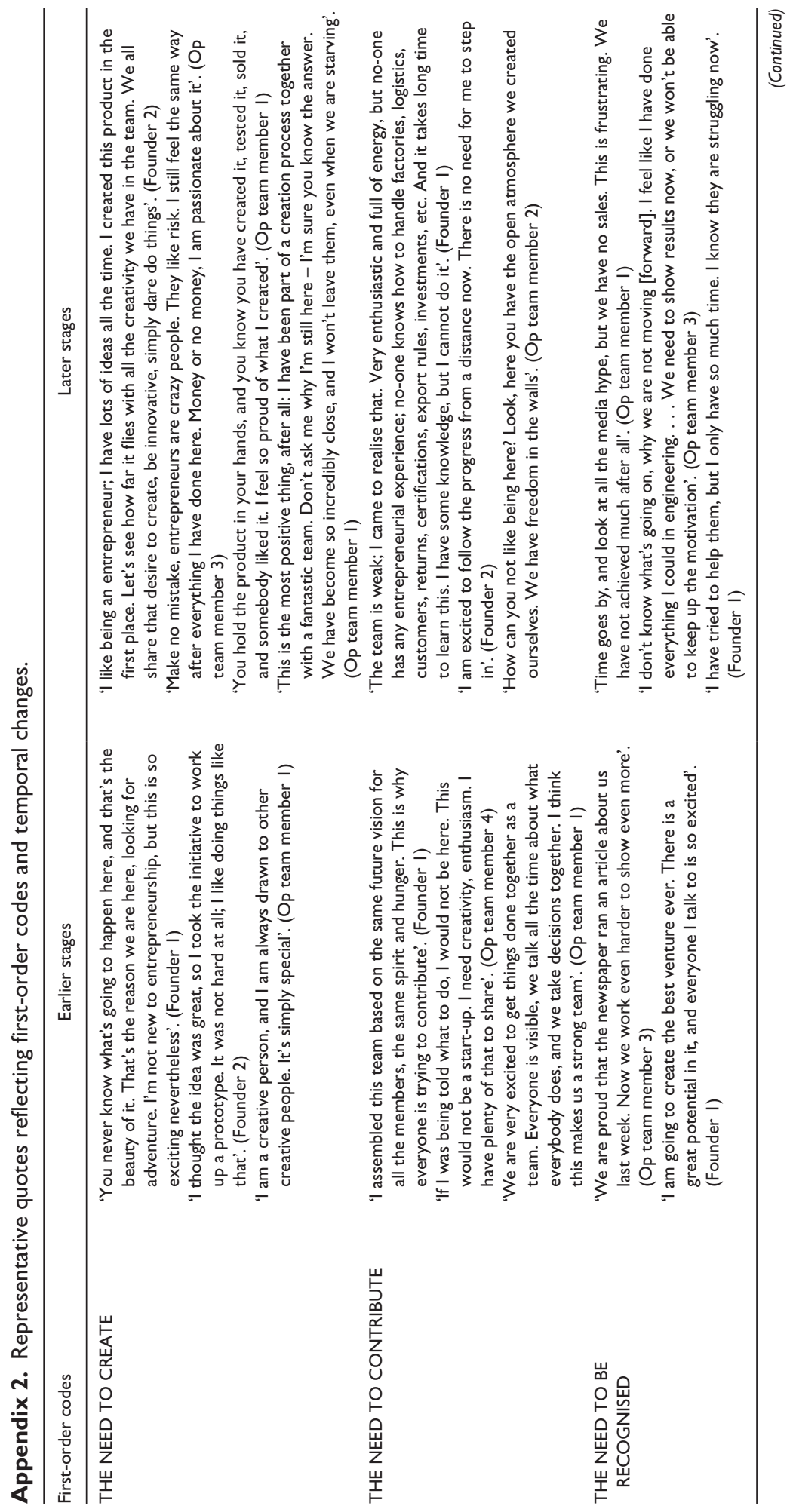




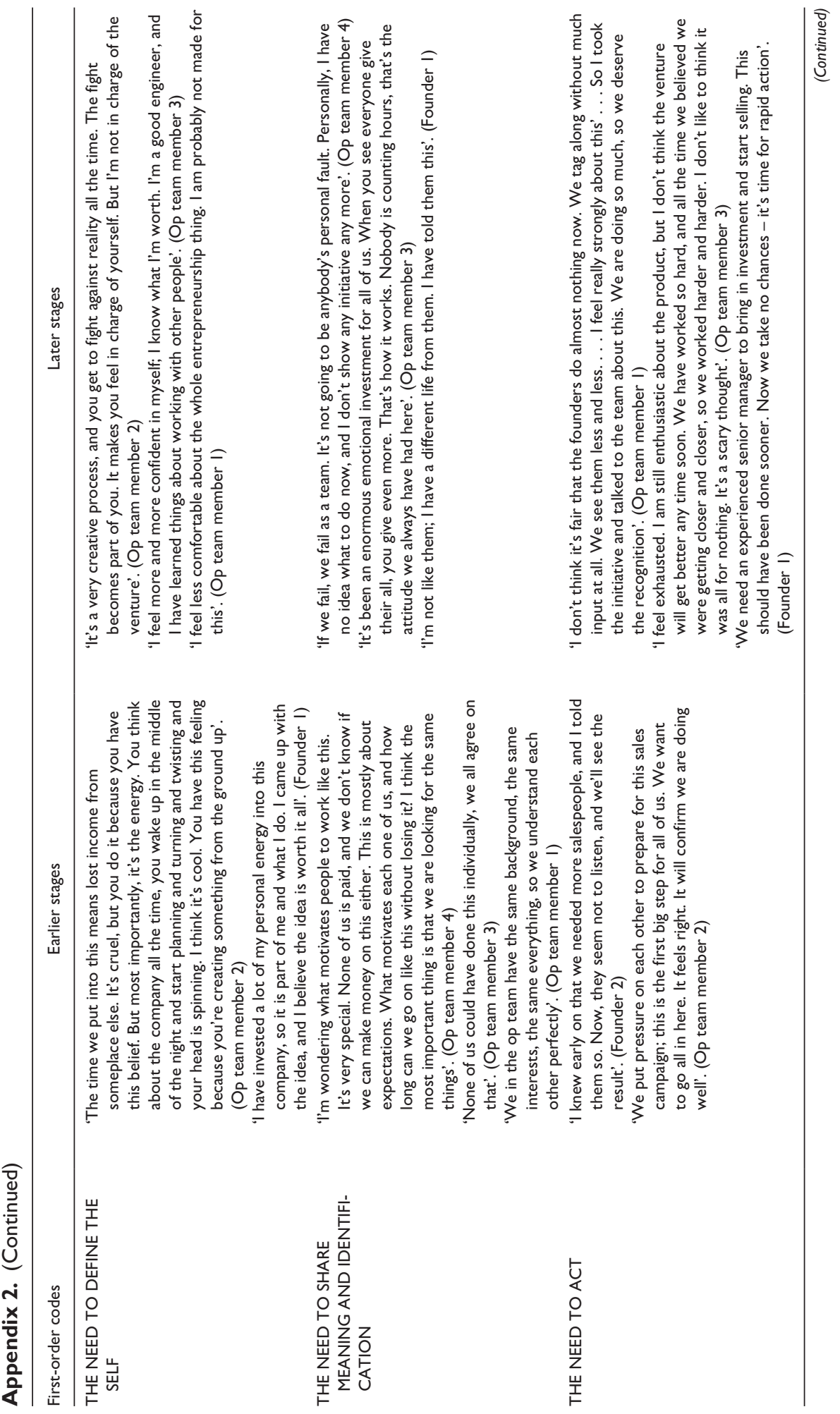




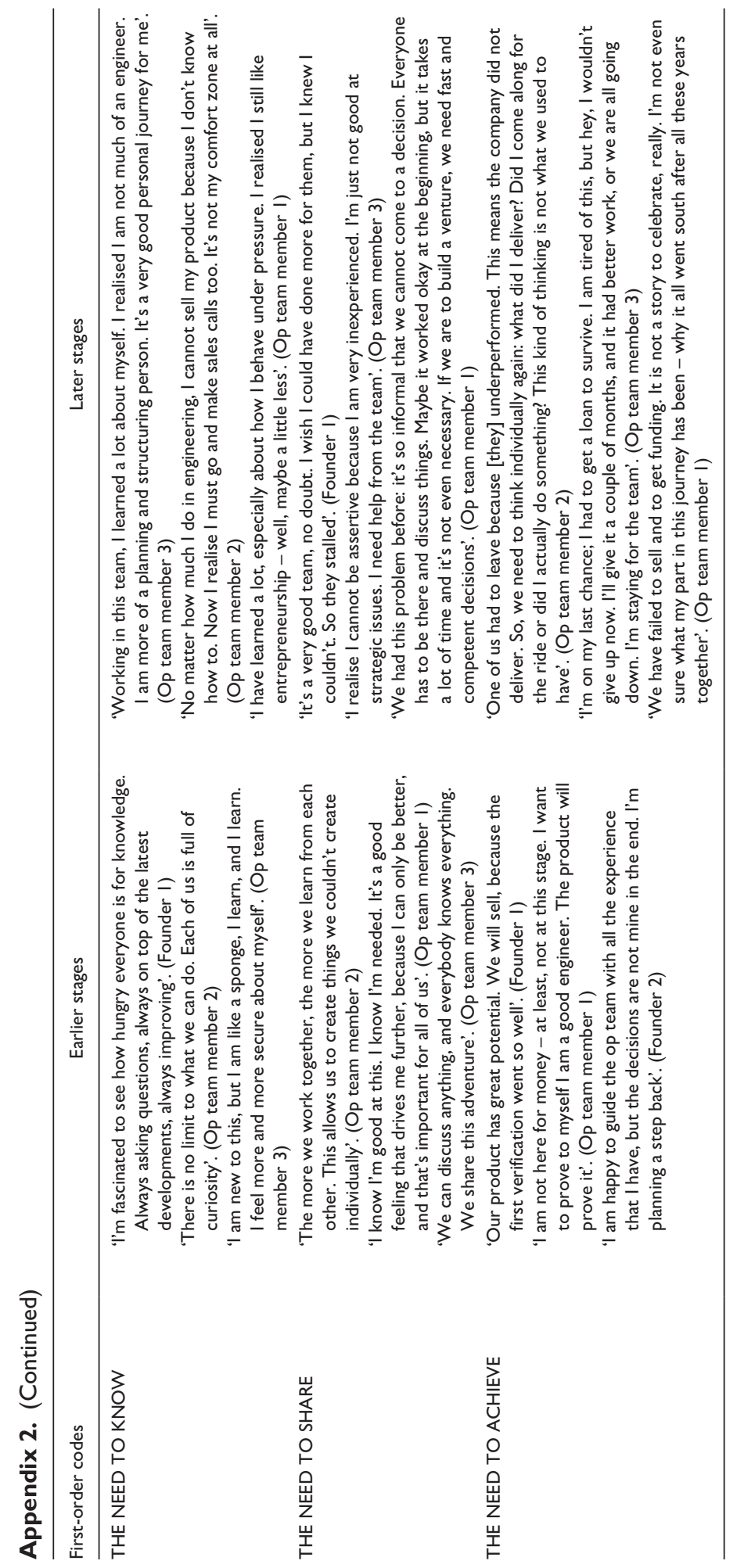

